\title{
HUMOR PERMAINAN KATA DALAM CERITA SI PALUI
}

\author{
Dana Aswadi ${ }^{1}$ \\ 1. Program Studi Pendidikan Bahasa dan Sastra Indonesia \\ STKIP PGRI Banjarmasin \\ dadan899@yahoo.co.id (085251406883)
}

\begin{abstract}
ABSTRAK
Cerita si Palui merupakan karya sastra yang menggambarkan salah satu aspek kehidupan masyarakat di Kalimantan Selatan. Humor permainan kata menjadi salah satu aspek yang membuat cerita si Palui ini disukai oleh para pembaca. Penelitian ini menganalisis cerita si Palui.Penelitian ini bertujuan (1) memperoleh gambaran tentang humor permainan kata dalam ceirta si Palui dan (2) mengetahui makna humor dalam cerita si Palui. Pendekatan yang digunakan dalam penulisan ini adalah pendekatan deskriptif kualitatif, yaitu data-data secara tertulis digambarkan secara cermat. Sumber data penelitian diambil dari cerita si Palui yang terbit di harian Banjarmasin Post. Pemilihan data berdasarkan kesesuaian data dengan rumusan masalah. Teknik pengumpulan data yang digunakan dalam penelitian ini adalah dokumentasi dan studi pustaka. Teknik analisis data yang digunakan adalah teknik analisis isi, yaitu suatu teknik penelitian untuk membuat inferensi-inferensi yang dapat ditiru dan sahih data dengan memperhatikan konteksnya. Penelitian ini menetapkan keabsahan data dengan teknik pemeriksaan. Kriteria yang digunakan dalam keabsahan data, yaitu derajat kepercayaan dengan teknik pemeriksaan; perpanjangan keikutsertaan, ketekunan pengamatan, triangulasi, mendiskusikannya dengan teman sejawat, kecukupan referensial, membaca dan menelaah berkali-kali data-data yang telah dikumpulkan, menginventarisasi serta membaca berbagai pustaka dan dokumen, dan membaca dan menelaah berbagai teori yang membahas tentang sastra dan humor. Hasil penelitian ini berkenaan dengan humor permainan kata, yaitu berupa gambaran humor permainan kata dalam cerita si Palui.
\end{abstract}

Kata Kunci: Humor Permainan Kata, Cerita Si Palui

\section{A. Latar Belakang}

\section{PENDAHULUAN}

Masyarakat yang berada di Kalimantan Selatan merupakan salah satu masyarakat yang mempunyai kebudayaan daerah atau kearifan lokal yang membangun kekayaan budaya Nusantara atau kebudayaan Indonesia. Kebudayaan Nusantara tidak terlepas dari keberagaman kebudayaan daerah, terutama yang berhubungan dengan sastra. Sastra sudah sejak zaman dulu dilakoni oleh masyarakat di Kalimantan Selatan. Masyarakat yang berada di Kalimantan Selatan bukan hanya mempunyai ragam budayanya, tetapi juga dikenal dengan kepercayaannya. Kepercayaan dianggap masyarakat sebagai tempat menenangkan hati dari hal-hal yang membebaninya. Masyarakat Kalimantan Selatan disebut orang Banjar. Kebudayaan daerah dan kepercayaan orang Banjar tercermin dari karya sastra yang dibuat oleh masyarakat itu sendiri. Zaman dulu, orang Banjar menggunakan sastra sebagai sarana untuk menyampaikan informasi, baik masalah sosial, kepercayaan dan sebagainya. Orang Banjar juga menggunakan sastra sebagai sarana pengekspresian diri, baik marah, benci, senang, bahagia, dan sebagainya.

Sastra yang digunakan oleh orang Banjar sebelum mengenal aksara, berupa sastra lisan. Sastra lisan sudah berkembang sejak dulu di masyarakat Banjar. Sastra lisan tersebut antara lain digunakan seorang ibu untuk menidurkan anaknya (dindang anak), cerita-cerita 
yang digunakan oleh orang yang ahli cerita (tukang kisah) mampu menceritakannya di tengah-tengah rakyat. Cerita-cerita itu bisa berisi tentang sosial, pendidikan, maupun kepercayaan masyarakat. Kemudian, setelah masyarakat mengenal aksara, maka lahirlah sastra tertulis. Sastra tertulis menjadi sarana yang diminati oleh para pembuat karya sastra dalam mendokumentasikan karyanya. Sastra sudah dekat dengan masyarakat sejak zaman dulu, sehingga pembuatan karya sastra pun tidak terlepas dari situasi dan kondisi pada saat itu.

Sastra tidak terlepas dari bahasa, karena bahasa merupakan medium yang digunakan oleh manusia dalam menyampaikan suatu hal dalam dirinya, baik berupa informasi, perintah, maupun yang lainnya. Bahasa juga menjadi sarana dalam menyampaikan sebuah perasaan, baik perasaan sedih, senang, bahagia, marah, dan sebagainya. Bahasa yang disampaikan dalam sastra merupakan media dalam penyampaian perasaan.

Sastra adalah suatu bentuk dan hasil pekerjaan seni kreatif yang obyeknya adalah manusia dan kehidupannya dengan menggunakan bahasa sebagai mediumnya (Semi, 1988: 8). Karya sastra digunakan oleh pengarang untuk menyampaikan pikiran serta pendapatnya terhadap sesuatu yang secara realitas terjadi dalam kehidupan masyarakat, yang menjadi salah satu alasan kenapa pengarang membuat karya sastra.Pengarang menggunakan pikirannya dalam membuat karya sastra, bahasa digunakan untuk mengungkapkan segala informasi serta perasaan dari pengarang yang disesuaikan dengan realitas yang ada di masyarakat dengan ketelitian dan rasa seni yang besar agar karyanya disukai oleh para pembaca.Sastra tidak terlepas dari keadaan masyarakatnya. Setiap karya sastra mempunyai perbedaan keunikan dalam karyanya. Setiap sastra mempunyai keunikan dan maksud tersendiri, dan semua itu dikarenakan letak lingkungan pengarang, keadaan pengarang, atau situasi saat pengarang tersebut menciptakan karya sastra.yang indah dan berusaha menyalurkan kebutuhan keindahan manusia (Semi, 1988: 8).

Sastra memberikan keindahan bagi penikmatnya, ketika berbicara tentang sastra pastinya tidak akan terlepas dari pencipta/pengarang karya sastra tersebut. Dalam karya sastra ada maksud yang ingin disampaikan oleh seorang pengarang, dan setiap karya sastra mempunyai perbedaan-perbedaan dalam karya sastranya. Hal ini dikarenakan keadaan si pengarang ketika membuat karya sastra, baik karena lingkungan pengarang, situasi pengarang, atau situasi pengarang tersebut. Setiap karya sastra pasti mempunyai keunikan dan perbedaan keunikannya karena sastra tidak terlepas dari masyarakat setempat. Karya sastra merupakan karya kreatif, sehingga sastra harus mampu melahirkan suatu kreasi yang dapat membangkitkan nilai estetika serta pandangan dari pembacanya. Bukan hanya sebagai karya kreatif, sastra juga merupakan karya yang imajinatif dan merupakan pandangan dari realitas masyarakat. Karya sastra yang terdapat di Nusantara ini tidak terlepas dari peran sastra daerah. Para sastrawan menuangkan seluruh pikiran dan perasaan dalam sebuah karya sastra. Sastra daerah tersebut ada yang dilisankan dan ada yang tertulis.

Sastra daerah merupakan karya sastra yang memberikan kontribusi yang besar terhadap kekayaan sastra Nusantara. Sastra daerah tercermin dari setiap aspek kehidupan masyarakat yang menjadi tempat terciptanya karya sastra, karena sastra daerah cerminan kebudayaan masyarakatnya. Perhatian masyarakat terhadap karya sastra sangat diperlukan untuk melestarikan ciri khas serta kebudayaan masyarakat. Agar tidak punah, maka diperlukan perhatian khusus dari para sastrawan dan juga para peneliti untuk melestarikan karya sastra. Karya sastra selalu berubah setiap waktu, tergantung pada keadaan masyarakatnya. Ketergantungan sastra pada masyarakat yang selalu berubah keadaannya seiring waktu, sehingga diperlukan perhatian khusus dari pemerintah terkait, para sastrawan, serta para peneliti dan masyarakatnya agar sastra yang selama ini berkembang dan menjadi ciri khas masyarakat tidak punah dan terhapus. 
Hermawan (2006: 25-26) menyatakan bahwa "Ada sekelompok karya sastra yang dikategorikan berdasarkan media publikasinya, seperti sastra koran, sastra majalah, sastra tabloid, sastra buku, sastra internet, sastra digital, dan sastra audio-visual. Ada juga karya yang dikelompokkan secara geografis, seperti tampak pada adanya istilah-istilah sastra dunia, sastra nasional, sastra daerah, sastra pedalaman, sastra pesisir, dan sastra kota. Keduanya masih dikelompokkan lagi berdasarkan kelisanan atau keberaaksaraannya sehingga ada istilah sastra lisan dan sastra tulisan". Sastra Indonesia modern di Kalsel identik dengan sastra koran/ majalah dan sastra buku. Sastra koran/ majalah adalah karya saastra yang dipublikasikan di koran/ majalah (Dinas Pemuda Olah Raga Kebudayaan dan Pariwisata, 2011: 1). Koran merupakan salah satu tempat yang sangat mendukung dan memberikan tempat bagi para sastrawan untuk menulis karyanya. Setiap sastra tersebut diuraikan dan ditulis kemudian disampaikan kepada masyarakat. Salah satu karya sastra yang menarik dan mempunyai nilai perhatian dari masyarakat adalah karya sastra yang berupa cerita. Karya sastra berupa cerita yang terkenal dan sudah menjadi gambaran kebudayaan orang Banjar adalah cerita Si Palui yang diterbitkan di harian Banjarmasin Post.

Cerita Si Palui pada awal dimuat di harian Banjarmasin Post merupakan cerita yang berasal dari sastra yang diturunkan dari mulut-ke mulut/secara lisan. Jadi, pada waktu itu, cerita Si Palui dimuat berdasarkan cerita rakyat. Penerbitan cerita Si Palui di harian Banjarmasin Post mendapat sambutan yang baik dari masyarakat, kemudian cerita Si Palui dibuat sedemikian rupa dan merupakan cerita yang penuh dengan humor. Pemuatan cerita $\mathrm{Si}$ Palui membuat orang yang membacanya menjadi geli dan tertawa, misalnya yang terdapat dalam kutipan cerita Si Palui berikut.

\section{“Nah susun kalimatnya dari kata-kata kucing-tahitikus-makan” ujar Palui. "Sutil banar... dangarakan jawabanku, tikus makan tahi kucing, tahi tikus makan kucing, tahi kucing makan tikus" ujar Garbus kumat-kamit mambulak-balik susunan kata-kata itu. ("Nah susun kalimatnya dari kata-kata kucing-tahitikus- makan" kata palui. "Gampang sekali...dengar jawabanku, tikus makan tahi kucing, tahi tikus makan kucing, tahi kucing makan tikus," kata Garbus membolak-balikkan (Kucing Makan Tikus).}

Kutipan ini menceritakan Garbus yang merangkai kata yang diberikan oleh Palui. Garbus membuat permainan kata dengan membolak-balik kata, sehingga tercipta kalimat yang menunjukkan keganjilan. Permainan kata ini memberikan rasa geli dan memunculkan lelucon bagi pembacanya.Penelitian ini merupakan kajian yang diterapkan dan berada pada teks cerita Si Palui. Peneliti lebih berorientasi pada teks permainan kata yang terdapat dalam cerita Si Palui di harian Banjarmasin Post yang dihubungkan dengan unsur yang membangun kelucuan.

\section{B. Tujuan Penelitian}

Adapun tujuan penelitian ini untuk mengetahui:

a. gambaran mengenai humor permainan kata

b. mengetahui makna humor permainan kata.

\section{METODOLOGI PENELITIAN}

\section{A. Pendekatan dan Metode Penelitian}

Pendekatan yang digunakan peneliti dalam meneliti jenis dan makna humor yang terdapat dalam cerita Si Palui adalah pendekatan deskriptif kualitatif. Bogdan dan Miller (dalam Moleong, 2000: 3) mengemukakan bahwa penelitian kualitatif adalah penelitian yang mengahasilkan data deskriptif berupa kata-kata tertulis atau lisan dari orang-orang atau 
perilaku yang diamati. Jabrohim (2002, 31-32) mengemukakan bahwa; metode deskriptif merupakan gambaran secara tepat sifat-sifat individu, atau gejala yang terjadi secara nyata.

Pendekatan kualitatif sangat relevan dengan penelitian yang akan diteliti, dan pendekatan kualitatif digunakan dengan alasan bahwa yang menjadi fokus penelitian adalah berupa cerita dalam bentuk tertulis dalam beberapa teks judul cerita Si Palui dalam harian Banjarmasin Post. Pendekatan deskriptif bertujuan untuk mengumpulkan, mengklasifikasi, dan menganalisis data sehingga diperoleh gambaran dari makna dan fungsi humor permainan kata dalam cerita Si Palui.

Karya sastra perlu ditafsirkan sebab di satu pihak karya sastra terdiri atas bahasa, di pihak lain, di dalam bahasa sangat banyak makna yang tersembunyi, atau disengaja disembunyikan (Ratna, 2004: 45). Thompson (2005: 67) mengatakan bahwa hermeneutika merupakan satu disiplin yang perhatian utamanya dicurahkan pada aturan-aturan penafsiran terhadap teks yang jelas. Hermeneutika merupakan jenis penelitian yang relevan dengan penelitian ini. Hermeneutika merupakan jenis penelitian yang meneliti teks sebagai objeknya untuk menemukan makna yang terkandung di dalamnya. Penelitian ini menggunakan teks sebagai objeknya, dan penelitian ini berkisar dari teks yang terdapat dalam cerita Si Palui.

Dalam sastra, pembicaraannya terbatas sebagai metode. Di antara metode-metode yang lain, hermeneutika merupakan metode yang paling sering digunakan dalam penelitian karya sastra (Ratna, 2004: 44). Teori hermeneutika Ricoeur berusaha mengintegrasikan eksplanasi dan pemahaman dengan dialektika yang konstruktif yang terdapat di dalam khazanah teks.

\section{B. Sumber Data}

Penelitian ini menggunakan data yang dikumpulkan dari cerita Si Palui yang bersumber dari media cetak harian Banjarmasin Post yang dikumpulkan selama tiga bulan. Data tersebut sesuai dengan teknik yang digunakan dalam pendekatan deskriptif kualitatif, yakni pertama dikumpulkan semua data tersebut setiap harinya kemudian dipilah-pilah yang relevan dengan rumusan masalah yang akan diteliti. Setelah dikumpulkan maka diklasifikasikan data tersebut, dibagi mana saja yang sejenis dengan apa yang ingin diteliti, yakni dibagi berdasarkan jenis dan makna. Ketiga, setelah data terkumpul dan dipilah atau dibagi sesuai dengan apa yang ingin diteliti, sehingga diperoleh beberapa cerita yang relevan dan bisa digunakan sebagai data yang akan menjadi sumbernya, kemudian dianalisis sesuai dengan data tersebut.

\section{Teknik Analisis Data}

Teknik yang digunakan, yakni teknik analisis isi dari Krippendorf. Krippendorff (1993:

15) mengasumsikan bahwa analisis isi adalah suatu teknik penelitian untuk membuat inferensi-inferensi yang dapat ditiru dan sahih data dengan memperhatikan konteksnya. Data penelitian ini dianalisis dengan langkah-langkah sebagai berikut:

a. Pembentukan data; data umum yang berupa teks dari cerita Si Palui yang terbit di harian Banjarmasin Post dikumpulkan, sehingga data mengungkapkan kaitan antara sumber informasi dan bentuk simbolik.

b. Unitisasi; pengambilan data secara tepat. Data yang akan diambil berupa teks dari cerita Si Palui yang terbit di harian Banjarmasin Post.

c. Sampling; tahap ini menganalisis dan merangkum unit-unit yang telah dikumpulkan. Adapun dalam penelitian yang berupa kualitatif, maka kutipan-kutipan dan contohcontoh dijadikan sebagai fungsi yang sama dengan sampel. Sampling digunakan sebagai pendukung dalam pernyataan utama dari penelitian.

d. Pencatatan; setiap unit harus diberi pengkodean dan dideskripsikan dalam bentuk yang dapat dianalisis. Tahap ini mengharuskan peneliti melakukan pencatatan. 
e. Reduksi data; tahap ini memerlukan data yang efisien, sehingga data yang dikumpulkan dari unit-unit menjadi lebih singkat, padat, dan jelas.

f. Penarikan inferensi; pada tahap ini merupakan sebuah analisis yang menjelaskan secara rinci, yakni mencari makna-makna dari unit-unit yang telah dikumpulkan.

g. Analisis; menyangkut proses secara konvensional, berisi informasi-informasi yang bersifat menjelaskan atau deskriptif terhadap analisis isi. Tahap ini merupakan tahap terakhir, sesudah data terkumpul dan dibagi secara perunitnya serta memberikan makna konteksnya, setelah itu maka dianalisis setiap komponennya dan dideskrifsikan secara eksplisit.

\section{HASIL PENELITIAN DAN PEMBAHASAN}

\section{A. Gambaran Humor Permainan Kata dalam Cerita Si Palui}

Humor permainan kata ialah humor yang berhubungan dengan permainan kata dari tataran linguistiknya. Perubahan tataran linguistik bisa dari fonem, morfem, maupun kalimatnya. Perubahan bunyi pada salah satu kata yang secara sengaja atau tidak sengaja berbeda bisa memunculkan makna yang lucu. Menurut Yunus, dkk (1997) bahwa humor permainan kata adalah humor yang memiliki kata-kata yang sama ucapannya, tetapi berbeda makna dan ejaannya. Humor permainan kata ini juga dibangun dengan pertanyaan. Pertanyaan ini berupa teka-teki yang membangun lelucon, sehingga pembaca merasa lelucon ini merupakan suatu hal yang menarik. Humor teka-teki mempunyai persamaan dengan permainan kata, tetapi dalam humor teka-teki selalu dimulai dengan pertanyaan yang diikuti jawaban. Teka-teki bisa dibentuk dari pertanyaan yang berhubungan dengan diri sendiri, sosial, maupun yang berhubungan dengan keadaan lingkungan. Lihat kutipan berikut.

"Manurutku alasannya salain kolot alias katinggalan jaman, jua gasan mahindari kalu-kalu kita tasalah ucap atawa tasalah dangar. Atawa tabalujur kita latah kagigiran... Eh ipukku... ipukku... lalu tasalah ucap, aksara 'u' taucap aksara 'i', labar am, pasti kita disumpahi bubuhan bibinian." ("Menurutku alasannya selain kolot atau ketinggalan zaman, itu juga untuk menghindari apabila kita salah mengucapkannya atau salah dengar. Atau kebetulan kita latah... Eh ipukku...ipukku...kemudian salah mengucapkan, aksara "u" mengucap 'i', maka am, pasti kita disumpah perempuan”). (Kisah Ipuk Salipi).

Teks tersebut menunjukkan perubahan bunyi pada huruf dari " $u$ " menjadi " $i$ " merupakan perubahan fonem yang memunculkan rasa geli bagi pembaca. Perubahan ini disebabkan oleh beberapa faktor terutama diungkapkan oleh penulis disebabkan salah ucap. Salah ucap ini terjadi disebabkan terkejut atau adanya unsur ketidaksengajaan dengan pembebasan ekspresi, sehingga ketika mendengar perubahan bunyi ini langsung memunculkan rasa geli dan lucu.

Teks tersebut juga menunjukkan permainan kata. Permainan kata pada peristiwa ini dari kata-kata yang disusun menjadi kalimat, sehingga memiliki arti. Kata-kata bisa disusun dan bisa memunculkan makna yang baru. Lihat kutipan berikut.

“Nah susun kalimatnya dari kata-kata kucing-tahitikus-makan” ujar Palui.

"Sutil banar... dangarakan jawabanku, tikus makan tahi kucing, tahi tikus makan kucing, tahi kucing makan tikus" ujar Garbus kumat-kamit mambulak-balik susunan kata-kata itu. ("Nah susun kalimatnya dari kata-kata kucing-tahitikus-makan" kata palui. "Gampang sekali...dengar jawabanku, tikus makan tahi kucing, tahi tikus makan kucing, tahi kucing makan tikus," kata Garbus membolak-balikkan (Kucing Makan Tikus). 
Teks tersebut menunjukkan susunan kata dari kucing-tahitikus-makan yang dibolakbalikkan sehingga memiliki makna yang berbeda-beda. Pembalikan kata tersebut memunculkan makna yang tidak lazim atau sesuai. Susunan kata ini menjadi kalimat yang disusun secara rapi oleh Garbus, tetapi yang membuat peristiwa ini menjadi lucu dan geli bagi para pembaca adalah susunan kata menjadi kalimat yang disusun oleh Garbus mempunyai makna yang tidak lazim. Ketidaklaziman makna ini terdapat pada susunan kata tikus makan tahi kucing, tahi tikus makan kucing, dan tahi kucing makan tikus. Dalam tataran bahasa indonesia tidak ada makna kotoran (pesis) memakan benda. Jawaban Garbus menyusun kata-kata ini menjadi kalimat membuat pembaca merasa geli dan tertawa.

Teks tersebut menunjukkan kata yang disusun dari kata kucing, makan, tahi tikus. Palui memberikan susunan kata ini kepada Garbus yang merasa pintar ketika ikut sekolah paket. Garbus menyusun dengan rapi kata demi kata dan membolak-balikannya sehingga terbentuk beberapa pola kata dari susunan kata yang diberikan Palui. Garbus dalam kutipan tersebut masih belum bisa dan memahami menyusun kata yang diajukan oleh Palui. Dia membuat kata "kotoran/tahi" pada setiap pola katanya dan setiap polanya terbolak-balik tidak teratur. Kata yang dirangkai Garbus ini selalu menggunakan kata "kotoran/tahi", padahal tidak ada kata "kotoran/tahi" itu apabila menyusun kalimat dari kata-kata ini. Palui pun kemudian mengungkapkan bahwa susunan yang benar adalah "kucing makan tikus". Garbus menanyakan dimana letak tahinya dan Palui menjawab "kotoran/tahi" muncul apabila ditunggu beberapa menit setelah kucing makan tikus. Kelucuan dalam peristiwa ini juga ditunjukkan pada kotoran "tahi" yang memakan kucing atau tikus.

Teks berikut ini menceritakan permasalahan yang terjadi di Indonesia salah satunya adalah pemalsuan. Pemalsuan sering terjadi dilakukan oleh oknom-oknom yang tidak bertanggung jawab. Pemerintah diharapkan bisa memberikan hukuman dan menindak bagi para oknom pemalsuan ini, sehingga ada efek jera dan tidak mengulanginya lagi. Peristiwa pada kutipanberikut menceritakan pemalsuan yang terjadi di Indonesia.

\begin{abstract}
Ini bukan kisah maaspal kartak, tapi kisah aspal asli tapi palsu (Aspal), ujar Garbus.

Bah...ini kisah mangaradau haja, Bus ai. Kalu asli... yang asli, kada palsu ya palsu tipang. Mun aku kada salah pandangar, di banua kita ini banyak banar kasus palsu memalsukan, ujar Tuhirang kada mau kalah. Aku gin mandangar kisah uang palsu alias upal, ijazah palsu alias izpal, kasit atawa kaspal Wan lainlain, mungkin barang kali baluman tarungkap, ujar Tuhirang. (Ini bukan cerita mengaspal kertak, tetapi kcerita aspal asli tetapi palsu (Aspal), kata Garbus. Bah...ini cerita sembarang saja, Bus. Apabila asli...yang asli, tidak palsu ya palsu saja. Bila aku tidak salah dengar, di benua kita ini sering terjadi kasus palsu memalsukan, kata Tuhirang tidak mau kalah. Aku juga mendengar cerita uang palsu alias upal, ijazah palsu alias izpal, kaset atau kaspal dan lain-lain, kemungkinan tidak terungkap lagi, kata Tuhirang). (Saraba Palsu).
\end{abstract}

Teks tersebut menunjukkan permainan kata berupa singkatan dari gabungan kata. Teks berupa singkatan gabungan kata memunculkan ekspresi pembaca. Singkatan-singkatan gabungan kata ini sebagai cara penulis untuk menarik minat pembaca. Pembaca pun merasa terhibur dan tertawa ketika membaca singakat-singkatan dari gabungan kata yang terdapat pada kutipan peristiwa ini. Singkatan dari gabungan kata juga terdapat pada "P.10-MK.a". Kutipan berikut ini menceritakan Palui yang mengadakan selamatan di rumahnya. Istri Palui sakit, sehingga Palui yang memasak. Masakan Palui ini tidak sesuai dengan yang diharapkan, karena ternyata rasanya asin. Lihat kutipan berikut. 
“Kanapa maka dipadahakan masakan koki,” ujar Garbus takurasam kamasinan. "Biniku gagaringan jadi aku nang bamasak, masak koki itu artinya masak laki," sahut Palui. ("Kenapa dikatakan masakan koki," kata Garbus keasinan. "istriku sakit jadi aku yang memasak, masakan koki itu artinya masakan laki," Palui menyahut). (Masakan Koki)

Teks tersebut menunjukkan singkatan dari gabungan kata. Kelucuan dari peristiwa ini ketika Garbus yang tidak memahami singkatan yang diberikan oleh Palui. Garbus menafsirkan bahwa masakan koki adalah masakan yang dimasak oleh tukang masak yang berada di resturan atau hotel. Sewaktu memakan masakan ini rasanya asin, sehingga Garbus pun bingung terdapat masakan yang asin yang di masak oleh koki. Masakan koki yang dimaksud oleh palui disini adalah masakan koki.

Teks berikut ini menceritakan Palui yang mampir diwarung dan disana dia mendengar pakacil Alui dan pakacil Aban main tebak-tebakan masalah itik. Masing-masing sudah mengajukan teka-tekinya dan masing-masing juga tidak bisa menjawab teka-teki lawannya. Palui yang sudah lama mendengarkan akhirnya ikut juga bicara dan melemparkan teka-teki. Lihat kutipan berikut.

Palui kada kawa manahan hati lalu umpat jua bapander; Ulun ampun maaf, umpat jua manyurung pander ujar Palui.

Ayu, silahakan haja sambil bararamian ujar Aban. Kalu pakacil Aban wan pakacil Alui tadi masing-masing kawa manangguh anak itik laki wan anak itik bini, nang lainnya kawa manangguh hintalu itik laki wan hintalu itik bini, maka aku kawa manangguh itik laki wan itik bini itu wayah matan inya bakumpul, wayah inya maulah hintalu ujar Palui.

Waaahhh...... mana mungkiiinnn ujar Aban wan Alui taimbai mangaramputakan. Lainnya mana mungkin lagi.... tapi pasti aku kawa manangguhnya ujar Palui. Jawabannya adalah ......bahwa itik laki pasti nang diatas sadangkan itik bininya pasti nang dibawah sahut Palui sambil lihum kada hakun kalah dalam pander bahaharatan itu.(Palui tidak bisa menahan hati kemudian ikut bicara; Saya mohon maaf, ikut juga membuka pembicaraan. Ayo, silahkan saja sambil hiburan kata Aban. Apabila pakacil Aban dan pakacil Alui tadi masing-masing bisa menebak anak itik laki dan anak itik bini, yang lainnya bisa menebak telor itik laki dan telor itik bini, maka aku bisa menebak itik laki dan itik bini sewaktu mulai dia berkumpul, sewaktu dia membuat telor kata Palui. Waaahhh....mana mungkiiinnn kata Aban dan Alui berbarengan mendustakan. Lainnya tidak mungkin lagi...tetapi pasti aku bisa menebaknya kata Palui. Jawabannya adalah...bahwa itik laki pati diatas sedangkan itik bini pasti yang dibawah sahut Palui sambil senyum tidak mau kalah dalam pembicaraan tebakan). (Manangguh Laki Bini).

Teks tersebut mengandung lelucon yang menunjukkan kesinkronan teka-teki. Kesinkronan ini merupakan peristiwa yang bisa memunculkan rasa geli dan tawa. Palui yang sudah lama mndengarkan pakacil Aban dan pakacil Alui bermain teka-teki tentang itik laki dan itik bini juga ikut mengajukan teka-teki. Pakacil Aban dan pakacil Alui yang mendengar teka-teki Palui merasa ketidakmungkinan bisa ditebak bahwa bisa diketahui itik laki dan itik bini ketika membuatnya. Ketidakmungkinan ini kemudian dijawab Palui bahwa itik laki diatas dan itik bini dibawah. Jawaban Palui ini merupakan ketidaksesuaian dari hal yang dihrapkan, pakacil Aban dan pakacil Alui tidak menyangka bahwa itu adalah jawaban dari teka-teki yang diajukan Palui. 
Teks berikut ini menceritakan teka-teki dengan permasalahan karung sebagai dasar kata pembentukan teka-tekinya. Palui membuat teka-teki tentang karung yang paling besar di dunia. Tulamak dan Garbus tidak bisa menjawab, karena mereka beranggapan bahwa tidak ada karung yang paling besar di dunia ini selain karung yang mereka katakan. Akhirnya, Tulamak dan Garbus menyerah tidak bisa menjawab teka-teki ini. Lihat kutipan berikut.

\begin{abstract}
"Handak tahu kah?” Karung nang paling ganal tu karung ampun Columbus," ujar Palui sambil kurihing-kurihing.

"Hau. Siapa Columbus tu? Kanapa bisa karung inya nang paling ganal?" ujar Tulamak panasaran.

"Buhan ikam ni kada ingat wan palajaran rahat kita di isdi bahari. Ibu guru ada kalu mangisahakan Columbus nang mangulilingi dunia? Ujar sidin Columbus mangarungi lautan. Han, lautan haja kawa dikarunginya, pasti ganal banar karung Columbus tu," ujar Palui pina musti. ("Mau tahu?" Karung yang paling besar itu karung milik Columbus," kata Palui sambil senyum. "Hau. Siapa Columbus itu? Kenapa bisa karung dia yang paling besar?" kata Tulamak penasaran. "Kalian ini pasti ingat dengan pelajaran sewaktu kita di SD dulu. Ibu guru ada menceritakan Columbus yang mengelilingi dunia? Kata beliau Columbus mengarungi lautan. Han, lautan saja bisa dikarunginya, pasti besar karung Columbus itu," kata Palui pina mesti).(Karung Paling Ganal)
\end{abstract}

Teks tersebut menunjukkan teka-teki dari kata karung. Palui membuat teka-teki dengan tebakan karung yang paling besar di dunia. Kelucuan pada teks ini terjadi ketika Tulamak dan Garbus menyerah karena setiap jawaban mereka selalu disalahkan oleh Palui. Terdapat ketidakselarasan jawaban yang diharapkan oleh Tulamak dan Garbus dengan jawaban Palui. Palui mengutarakan bahwa karung yang paling besar adalah karungnya Columbus dikarenakan pada waktu SD guru bercerita bahwa Columbus mengarungi lautan. Mengarungi lautan yang disampaikan Palui adalah lautan diletakkan ke dalam krung, hal ini sebenarnya untuk membodohi Garbus dan Tulamak. Mengarungi lautan sendiri artinya mengelilingi lautan, pembaca merasa ketidakselarasan jawaban ini adalah suatu hal yang membuat rasa geli dan tertawa.

Teks berikut ini menceritakan Palui yang digugat oleh Garbus dihadapan warga, karena dianggap sebagai pemimpin yang korupsi. Peristiwa tentang kepemimpinan memberikan kita pelajaran tentang seorang pemimpin. Pemimpin harus bersikaf adil dan memperjuangkan rakyat. Lihat kutipan berikut.

"Sabar, sabaaaarrr... Bus," ujar Palui. "Ayu kita buka lagi parjanjian nang sudah sama-sama kita tadatangani, disitu tatulis ganti rugi tanah nang dipakai gasan jalanan. Ayu pikirakan bujur-bujur napa arti ganti rugi itu, artinya bubuhan ikam hakun diganti walaupun rugi.

Maka itu tarimalah ganti rugi itu sabarapa adanya sasuai nang kujulung dan jalanan libar ini dinikmati ulih bubuhan warga kita tamasuk warung ikam magin barami," ujar Palui manarangakan. ("Sabar, sabaaaarrr... Bus," kata Palui. "Ayo kita buka lagi perjanjian yang sama-sama sudah kita tandatangani, disitu tertulis ganti rugi tanah yang sudah dipakai untuk jalan. ayo pikirkan benar-benar apa arti ganti rugi itu, artinya kalian mau diganti walaupun rugi. maka dari itu terima saja ganti rugi itu walaupun seberapa adanya sesuai yang kuserahkan dan jalanan lebar ini dinikmati oleh warga termasuk warung kamu semakin ramai, “ kata Palui menerangkan). (Ganti Rugi : Minggu 17 Februari 2013). 
Teks tersebut menunjukkan lelucon yang berupa permainan kata yang berkenaan dengan makna yang ambigu. Permainan kata yang membuat lelucon pada kutipan ini terdapat pada perjanjian antara Palui dan warga. Warga tidak memahami dari teks yang dibuat Palui dalam perjanjian tanah. Tertulis dalam perjanjian bahwa warga mau di ganti rugi untuk tanah jalan. Palui mengungkapkan bahwa untung rugi yang dimaksud adalah warga mau diganti walaupun rugi. Permainan kata seperti ini membuat pembaca merasa geli dan tertawa, karena penjelasan Palui tentang ganti rugi.

Berdasarkan analisis yang telah dilakukan, maka humor permainan kata digambarkan pada beberapa cerita si Palui, yaitu Kisah Ipuk Salipi, Kucing Makan Tikus, Saraba Palsu, Masakan Koki, Manangguh Laki Bini, Katupat Bahintalu, Karung Paling Ganal, Ganti Rugi, Hintalu Batuk, Muntung Bini, Kana Razia Sajam, Batatangguhan Karak, Babanyakan Makna, Hutil Bintang Tujuh, dan Bahual Putungan.

\section{B. Makna Humor Permainan Kata dalam Cerita Si Palui}

Makna yang terkandung dalam humor permainan kata yang terdapat dalam cerita si Palui, yaitu (a) memberikan pendidikan,(b) memberikan kritik, (c)menarik perhatian, dan(d) memberikan penjelasan/pemahaman.

Tabel 1. Makna Humor dalam Cerita Si Palui.

\begin{tabular}{|c|c|c|}
\hline 1 & $\begin{array}{l}\text { "Sual atas-maatasi laki bini gawian gampang walaupun akibatnya } \\
\text { ganal," ujar Palui sambil lihum. } \\
\text { "Atas maatasi kaya apa," Lui ujar Tulamak. } \\
\text { "Ya, atas ma-atasi artinya bagagantian diatas," sahut Palui. } \\
\text { "Akibatnya nang ganal itu pang kaya apa Lui?" ujar Garbus. } \\
\text { "Naahhh.....bagagantian diatas itulah nang ganal akibatnya bila kita } \\
\text { batahan satumat," ujar Palui. } \\
\text { "Apa akibatnya? ujar Garbus makin handak tahu. } \\
\text { "Akibatnya mancangul pulang saikung bisa sigaluh atawa si } \\
\text { nanang," ujar Palui mangalak tatawa mangalahakan kakawalannya. } \\
\text { (Ganal Akibtanya) }\end{array}$ & $\begin{array}{l}\text { Menarik } \\
\text { Perhatian }\end{array}$ \\
\hline 2 & $\begin{array}{l}\text { "Manurutku alasannya salain kolot alias katinggalan jaman, jua } \\
\text { gasan mahindari kalu-kalu kita tasalah ucap atawa tasalah dangar. } \\
\text { Atawa tabalujur kita latah kagigiran... Eh ipukku... ipukku.... lalu } \\
\text { tasalah ucap, aksara 'u' taucap aksara 'i', labar am, pasti kita } \\
\text { disumpahi bubuhan bibinian. (Kisah Ipuk Salipi) }\end{array}$ & $\begin{array}{l}\text { Memberikan } \\
\text { Penjelasan/ } \\
\text { Pemahaman }\end{array}$ \\
\hline \multirow[t]{3}{*}{3} & $\begin{array}{l}\text { a. "Ikam itu sabujurnya kada mata karanjang lagi Bus ai, tapi } \\
\text { karanjangnya, baisi anak sudah talu ikung bapadah bujang tarus," } \\
\text { ujar Palui. (Kucing Makan Tikus) }\end{array}$ & $\begin{array}{l}\text { 1. Kritik } \\
\text { 2. Memberikan } \\
\text { Penjelasan/ } \\
\text { Pemahaman }\end{array}$ \\
\hline & $\begin{array}{l}\text { b. "Nah susun kalimatnya dari kata-kata kucing-tahitikus-makan" ujar } \\
\text { Palui. } \\
\text { "Sutil banar... dangarakan jawabanku, tikus makan tahi kucing, tahi } \\
\text { tikus makan kucing, tahi kucing makan tikus" ujar Garbus kumat- } \\
\text { kamit mambulak-balik susunan kata-kata itu. (Kucing Makan } \\
\text { Tikus) }\end{array}$ & Pendidikan \\
\hline & $\begin{array}{l}\text { c. "Jawaban nang bujur Bus ai adalah: kucing makan tikus" ujar Palui. } \\
\text { "Lalu dimana ma andak tahinya?" ujar Garbus. } \\
\text { "Tahinya itu badudi, hadangi sahari atawa dua hari pasti kucing itu } \\
\text { bahira mangaluarkan tahi," ujar Palui batandik marasa manang. } \\
\text { (Kucing Makan Tikus) }\end{array}$ & $\begin{array}{l}\text { 1. Pendidikan } \\
\text { 2. Memberikan } \\
\text { Penjelasan/ } \\
\text { Pemahaman }\end{array}$ \\
\hline
\end{tabular}




\begin{tabular}{|c|c|c|}
\hline 4 & $\begin{array}{l}\text { a. Ini bukan kisah maaspal kartak, tapi kisah aspal asli tapi palsu } \\
\text { (Aspal), ujar Garbus. } \\
\text { Bah...ini kisah mangaradau haja, Bus ai. Kalu asli... yang asli, } \\
\text { kada palsu ya palsu tipang. Mun aku kada salah pandangar, di } \\
\text { banua kita ini banyak banar kasus palsu memalsukan, ujar } \\
\text { Tuhirang kada mau kalah. Aku gin mandangar kisah uang palsu } \\
\text { alias upal, ijazah palsu alias izpal, kasit atawa kaspal Wan lain- } \\
\text { lain, mungkin barang kali baluman tarungkap, ujar Tuhirang. } \\
\text { (Saraba Palsu) }\end{array}$ & Kritik \\
\hline 5 & $\begin{array}{l}\text { Tangguh Bus, kanapa maka Palui pina bainggang bajalan, ujar } \\
\text { Tulamak. } \\
\text { Mungkin batisnya sakit karna tasalihu, ujar Garbus. } \\
\text { Palui itu talapak batisnya tumbalan jadi jalannya pina baangkat } \\
\text { baingkit, ujar Tuhirang umpat manangguh. } \\
\text { Manurut tanguhanku panyakit lawasnya baumpat pulang, ujar } \\
\text { Garbus. } \\
\text { Napa panyakit lawasnya Bus? ujar Tulamak. } \\
\text { Panyakit lawasnya adalah bisulan di paha atawa di tamping burit, } \\
\text { ujar Garbus tatawa. (Tasalah Tangguh) }\end{array}$ & $\begin{array}{l}\text { Menarik } \\
\text { Perhatian }\end{array}$ \\
\hline 6 & $\begin{array}{l}\text { a. Kada usah gair, Mak ai. Sa apa ada ganalnya rumah sakit naini. } \\
\text { Kada bataha sasat jua kalu, sahut Garbus sambil kaluar pada taksi. } \\
\text { Imbah naik ka lantai ampat, carii haja lagi ruangan Monster. Napa } \\
\text { ngalihnya, Mak? ujarnya lagi pina musti. } \\
\text { Huss!! lakas Palui managur Garbus. Ruangan Master, Bus ai, } \\
\text { ngarannya, ujar Palui. (Batinggal Saurangan) }\end{array}$ & $\begin{array}{l}\text { Memberikan } \\
\text { Penjelasan/ } \\
\text { Pemahaman }\end{array}$ \\
\hline & $\begin{array}{l}\text { b. Hau, napa maka ikam kaluar pulang, Bus? ujar Palui batakun. } \\
\text { Ayu ha buhan ikam badahulu naik. Aku badudi haja, handak } \\
\text { baimbai lawan ading naini. Kasihan kalu inya kada bakawal, ujar } \\
\text { Garbus. } \\
\text { Tapi babinian tadi mahancap mangalunyur ka dalam lip } \\
\text { maninggalakan Garbus, sambil baucap, Kalu macam itu, pian haja } \\
\text { saurangan nang batinggal. } \\
\text { Ulun handak badadas pang. Wan jua, kaina lip-nya mubajir kalu } \\
\text { kada diganapi jadi sapuluh ikung urangnya. } \\
\text { Nasib... nasib... ujar Garbus batapak kapala tapakalah } \\
\text { saurang.(Batinggal Saurangan) }\end{array}$ & Pendidikan \\
\hline 7 & $\begin{array}{l}\text { "Buktinya, inya kawa mambawa gunung dua bigi, kita lalakian } \\
\text { napa? cuma kuat mambawa hintalu dua bigi, itu gin ditulungi lih } \\
\text { burung," ujar Palui tatawa mangalakak pulang."Bujur banar, } \\
\text { bujur banar, aku sapandapat lawan ikam Lui ai. Contohnya acil } \\
\text { Irus, sudah parak tiga puluh tahun maarak gunung kada uyuh- } \\
\text { uyuh jua," ujar Tulamak."Munyak bubuhan ikam ni, mun } \\
\text { kusurung gunungku ini pasti barabut batitiga," ujar acil Irus } \\
\text { tambah kasarikan. Buhannya batambah bahimat tatawan. } \\
\text { (Mambawa Gunung) }\end{array}$ & $\begin{array}{l}\text { Menarik } \\
\text { Perhatian }\end{array}$ \\
\hline
\end{tabular}




\section{A. Simpulan}

\section{PENUTUP}

Humor permainan kata digambarkan dalam cerita-cerita si Palui dengan judul; Kisah Ipuk Salipi, Kucing Makan Tikus, Saraba Palsu, Masakan Koki, Manangguh Laki Bini, Katupat Bahintalu, Karung Paling Ganal, Ganti Rugi, Hintalu Batuk, Muntung Bini, Kana Razia Sajam, Batatangguhan Karak, Babanyakan Makna, Hutil Bintang Tujuh, dan Bahual Putungan.

Makna yang terkandung dalam humor permainan kata yang terdapat dalam cerita si Palui, yaitu (a) memberikan pendidikan, (b) memberikan kritik, (c)menarik perhatian, dan(d) memberikan penjelasan/pemahaman.

\section{B. Saran}

Saran yang dapat peneliti kemukakan dari hasil penelitian adalah sebagai berikut.

1. Penelitian yang berhubungan dengan humor selanjutnya perlu dilakukan secara mendalam. Hal ini disebabkan masalah humor adalah satu pembahasan yang menarik untuk diteliti karena berkenaan dengan psikologi orang yang dikenai oleh humor. Orang yang dikenai humor ini bisa membebaskan diri dari segala masalah hidup.

2. Penelitian yang berkenaan dengan sastra lokal sangat diperlukan bagi peneliti lainnya nanti agar lebih meningkatkan dan memperkenalkan kebudayaan lokal.

\section{DAFTAR RUJUKAN}

Dinas Pemuda Olah Raga Kebudayaan dan Pariwisata. 2011. Sastra Indonesia di Kalimantan Selatan Sebelum Perang (1930-1945). Banjarmasin: Pemerintah Provinsi Kalimantan Selatan.

Hermawan, Sainul. 2006. Teori Sastra dari Marxis sampai Rasis. Banjarmasin: PBS FKIP Universitas Lambung Mangkurat.

Jabrohim. 2002. Metodologi Penelitian Sastra. Yogyakarta: Prasetia Widya Pratama.

Krippendorf, Klaus. 1993. Analisis Isi: Pengantar Teori dan Metodologi. Terjemah Farid Wajidi. Jakarta: RajaGrafindo Persada.

Moleong, Lexy J. 2000. Metodologi Penelitian Kualitatif. Bandung: Remaja Rosdakarya.

Ratna, Nyoman Kutha. 2004. Teori, Metode, dan Teknik Penelitian Sastra. Yogyakarta: Pustaka Pelajar.

Semi, M. Atar. 1988. Anatomi sastra. Padang: Angkasa Raya.

Thompson, John B. 2005. Filsafat Bahasa dan Hermeneutik. Diterjemahkan oleh Abdullah Khozin Afandi. Surabaya: Visi Humanika.

Yunus, Bakhrum., dkk. 1997. Jenis dan Fungsi Humor dalam Masyarakat Aceh. Jakarta: Pusat Pembinaan dan Pengembangan Bahasa. 